\title{
The syntax of number marking: The view from bare nouns in Wolof
}

\section{Suzana Fong*}

\begin{abstract}
Several languages allow for their nominals to occur without any functional morphology; they are dubbed 'bare nominals'. BNs are often number-neutral, i.e., there is no commitment to a singular or plural interpretation. In Wolof, however, $\mathrm{BNs}$ are singular when unmodified. A plural interpretation becomes available only when a nominal-internal plural feature is exponed in the form of complementizer or possessum agreement. I propose an extension of Béjar \& Rezac's (2009) Person Licensing Condition to number: a marked number feature (i.e. plural) must be licensed by Agree. BNs in Wolof can in principle be singular or plural. In the absence of a nominal-internal probe that Agrees with the plural feature of the BN, the Number Licensing Condition is violated, causing the derivation to crash. Unmarked number, i.e., singular, does not obey the NLC, so the derivation converges, yielding a singular BN. However, if there is a nominal-internal number probe, which is realized as complementizer or possessum agreement, the NLC is satisfied, allowing a derivation to converge where the $\mathrm{BN}$ is plural. If correct, this analysis accounts for the unusual behavior of BNs in Wolof and provides further empirical support for the view that valued features are responsible for nominal licensing (Kalin, 2017, 2019).
\end{abstract}

Keywords. Wolof, bare nominal, number, number neutrality, feature licensing

1. Introduction. Wolof (Niger-Congo, Senegal) has several overt determiners (see Tamba et al. 2012). ${ }^{1}$
a. Xale y-i lekk-na-ñu gato b-i.
child CM.PL-DEF eat-NA-3PL cake CM.SG-DEF
'The children ate the cake.'
b. Xadi gis-na a-b sàcc.
Xadi see-NA.3SG INDEF-CM.SG thief
'Xadi saw a thief.'
c. Awa jàpp-na a-y sàcc.
Awa catch-NA.3SG INDEF-CM.PL thief
'Awa caught some thieves.'

(Tamba et al. , 2012, (2a/32a/33b), adapted)

\footnotetext{
* Many thanks to L. Touré for teaching me his language; this work would not be possible without him. Thank you also to P. Tang for her help. The Wolof data presented here were collected during Spring/2019 and Fall/2019 (Ken Hale Fund; MIT). For discussion and criticism, I am grateful to D. Fox, M. Hackl, S. Iatridou, M. Martinović, D. Pesetsky, N. Richards, R. Schwartzchild, G. Thoms, to the participants of ECO-5 2019 (UMD), and of presentations given at Syntax Square (May/2018, Oct/2018; MIT), Hungry Wugs (Apr/2019; MIT), Tardes de Lingüística na USP (Jun/2019; USP), AlphaUG (Jul/2019; British Academy), and LSA 2020 (Jan; New Orleans). Thank you also to F. Chen for sharing her Mandarin judgment with me and for useful comments. A heartfelt thank-you goes to all participants of a practice talk given at MIT (Sept/2019). All errors are of course my own. Author: Suzana Fong, Massachusetts Institute of Technology (sznfong@mit.edu).

${ }^{1}$ Abbreviations: $\mathrm{CAUS}=$ causative, $\mathrm{CM}=$ class marker, $\mathrm{COMP}=$ complementizer, $\mathrm{COP}=$ copula, $\mathrm{DEF}=\mathrm{definite}$, $\mathrm{GEN}=$ genitive, $\mathrm{IMPF}=$ imperfective, $\mathrm{ITER}=$ iterative, $\mathrm{NA}=$ sentential particle for neutral sentences $(n a), \mathrm{NEG}$ $=$ negation, $\mathrm{NON} . \mathrm{FIN}=$ nonfinite, $\mathrm{OBJ}=$ object, $\mathrm{OBL}=$ oblique, $\mathrm{PL}=$ plural, $\mathrm{POSS}=$ possessive, $\mathrm{PREP}=$ preposition, $\mathrm{PROG}=$ progressive, $\mathrm{RECIP}=$ reciprocal, $\mathrm{REFL}=$ reflexive, $\mathrm{SG}=$ singular .
} 
The determiner contains a class marker (CM; see Babou \& Loporcaro 2016) affix. The class marker also encodes number information. For instance, the form of the noun sàcc 'thief' remains constant in (1b) and (1c). Its number interpretation is encoded in the class marker affixed to the indefinite determiner: $b$ for singular and $y$ for plural.

Wolof also has bare nominals (BNs).

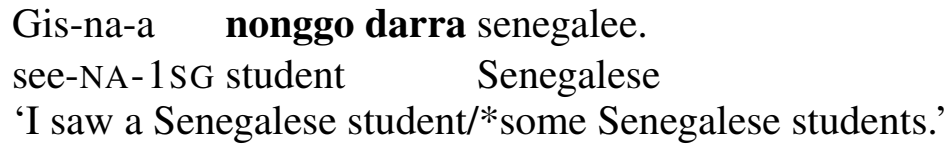

I assume that BNs are nominals that lack the functional morphology displayed by their overt counterparts (1). Thus, BNs in Wolof lack a(n overt determiner) and the class marker attached to it. Because of the absence of latter, there is also no overt number morphology.

BNs in Wolof seem to be indefinites. They can be licensed in an existential construction (3c), which displays definiteness effects:
a. Am-na a-b
/ a-y
xaj ci
biti.
have-NA.3SG INDEF-CM.SG / INDEF-CM.PL dog PREP outside
'There is a dog/are some dogs outside.'
b. *Am-na xaj b-i ci biti. have-NA.3SG dog CM.SG-DEF PREP outside Lit.: There is the dog outside.'
c. Am-na xaj ci tool b-i. have-NA.3SG dog PREP garden CM.SG-DEF
'There is a dog in the garden.' (NOT: There are dogs in the garden.)

Furthermore, they seem to take narrow scope:
Mareem séy-aat-na
ak fécckat.
Mareem marry-ITER-NA.3SG with dancer
'Mareem married a dancer again.'

$$
\checkmark \text { again }>\exists ; * \exists>\text { again }
$$

XMareem married the same dancer several times (e.g. marriage, followed by divorce, followed by another marriage).

$\checkmark$ Mareem has a very specific preference and she has married several, different dancers.

Several, unrelated languages have BNs too. One of them is Mandarin (Rullmann \& You, 2006; Jenks, 2018), which is illustrated below.

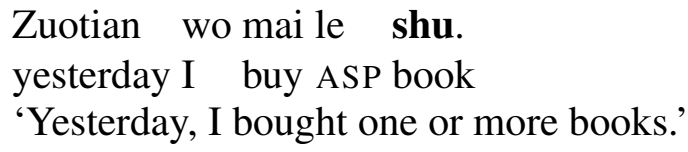

As can be gleaned from the translation in (5), BNs may have a number neutral interpretation, that is, they lack a commitment to a singular or plural interpretation (Corbett, 2000). Number neutrality can be demonstrated by, among other things, the possibility of the BN to saturate a collective predicate and to be referred back to with either a singular or plural pronoun. 
a. Zuotian wo mai le shu. Wo ba ta/tamen dai hui jia le. yesterday I buy ASP book. I BA it/them bring back home ASP 'Yesterday, I bought one or more books. I brought it/them home.'

b. Laoshi zai gongyuan-li jihe-le xuesheng.

(Rullmann \& You, 2006) teacher at park-in gather-PERF student 'The teacher gathered the students in the park.'

(F. Chen, p.c.)

Conversely, BNs in Wolof seem to be exclusively singular. Contrary to what happens in Mandarin, BNs in Wolof cannot saturate a collective predicate, or be the antecedent of plural discourse anaphora.
a. *Jangalekat b-i
dajeele-na xale ci bayaal b-i.
teacher CM.SG-DEF gather-NA.3SG child PREP park CM.SG-DEF
Lit.: 'The teacher gathered child in the park.'
b. Gis-na-a a-b jangalekat. Maymuna bëgg-na ko / *leen. see-NA-1SG INDEF-CM.SG teacher Maymuna like-NA.3SG OBJ.3SG / *OBJ.3PL 'I saw a teacher yesterday. Maymuna admires her/*them.'

Nonetheless, when a BN in Wolof is modified by a relative clause with plural morphology, it behaves as if it were a plural nominal. That the relative clause is plural can be inferred from the fact that it contains a plural class marker $y$. A BN thus modified can be the object of a collective predicate and be referred back to with plural discourse anaphora.
a. Jangalekat b-i
dajeele-na
xale $[\mathrm{RC} \mathrm{y}-\mathrm{u}$
Samba xam ] ci
teacher CM.SG-DEF gather-NA.3SG child [
CM.PL-COMP Samba know ] PREP
bayaal $b-i$.
park CM.SG-DEF
'The teacher gathered some students who Samba knows in the park.'
b. Gis-na-a jangalekat [RC y-u $\quad$ Roxaya xam ]. Maymuna bëgg-na
see-NA-1SG teacher [ CM.PL-COMP Roxaya know ] Maymuna like-NA.3SG
*ko / leen.
*OBJ.3SG / OBJ.3PL
'I saw some teachers who Roxaya knows. Maymuna admires them.'

Not every nominal modifier, however, has the same effect in the number interpretation of a Wolof $\mathrm{BN}$. In particular, if a $\mathrm{BN}$ is merged with a modifier (underlined) that does not have the syntax of a relative clause, as in (8a), it still behaves as if it were singular as regards the saturation of collective predicates and discourse anaphora.
a. *Roxaya dajeele-na fécckat brezilien. Roxaya gather-NA.3SG dancer $\overline{\text { Brazilian }}$ Lit.: 'Roxaya gathered Brazilian student.'
b. Gis na-a woykat brezilien. Maymuna bëgg na ko /*leen. see NA-1SG singer Brazilian Maymuna like NA.3SG OBJ.3SG / * OBJ.3PL 'I saw a Brazilian singer. Maymuna admires her/*them.


One of the differences between relative clauses and nationality modifiers lies in whether there is plural morphology in the modifier or not. The same difference will be shown to arise in two types of possessive constructions, one that has number morphology and one which does not; the presence or absence of number morphology will also correlate with the number interpretation of the BN. In view of this distinction, this paper aims at addressing the following questions:

a. How can we account for the exclusively singular interpretation (and not number neutral) interpretation of unmodified BNs in Wolof?

b. Why does a BN without any plural morphology behave as if it were singular, while a BN merged that does contain plural morphology behaves as if it were plural?

I will propose an extension of Béjar \& Rezac's (2009) Person Licensing Condition to number, according to which an interpretable instance of the feature [PLURAL] must be licensed by the operation Agree. A generalized need for certain features to be licensed has been proposed by Kalin (2017, 2019). The gist of the analysis is that BNs in Wolof can bear either a [SINGULAR] or a [PLURAL] feature. However, because [PLURAL] requires licensing by Agree, the equivalent construal only arises in the $\mathrm{BN}$ when there is a number probe inside the nominal that Agrees with the matching feature in the $\mathrm{BN}$. This would be the case, for instance, of relative clauses (8a), where number morphology appears in the class marker (CM) prefixed to the relative complementizer $u$. Conversely, in the absence of such a probe, as in (9a), only a BN with a [SINGULAR] feature leads to a convergent derivation, as this unmarked feature is stipulated not to require licensing by Agree.

2. Unmodified BNs in Wolof are singular. In this section, we will examine data that suggest that BNs in Wolof are singular.

First, a BN in Wolof cannot saturate a collective predicate. The verb dajeele 'gather' requires a plural object.

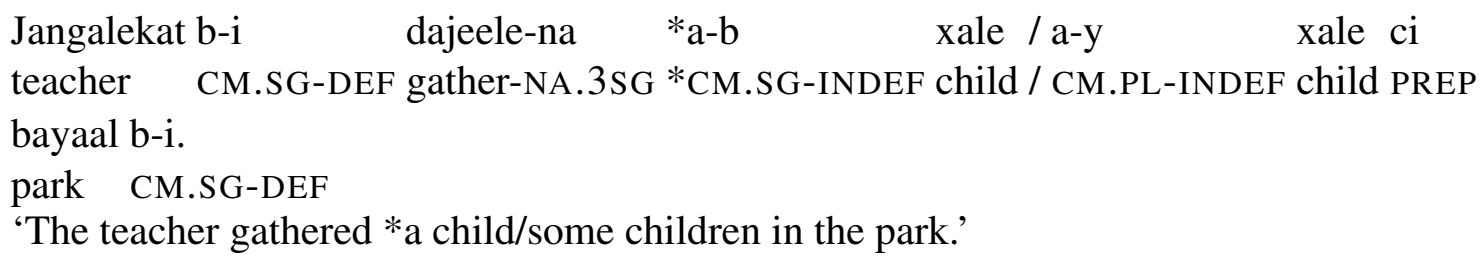

As we have already seen, a BN in Wolof cannot be the object of that verb (cf. Mandarin (6b)).
*Jangalekat b-i
dajeele-na xale ci bayaal b-i.
teacher CM.SG-DEF gather-NA.3SG child PREP park CM.SG-DEF
Lit.: 'The teacher gathered child in the park.'

A singular full nominal can be the object of a collective predicate, but only if an oblique argument ( $a$ k ab woykat 'with a singer') is added.
Faatu dajeele-na a-b
fécckat ak a-b woykat.
Faatu gather-NA.3SG INDEF-CM.PL dancer with INDEF-CM.SG singer
'Faatu gathered a dancer with a singer.' 
In that case, a BN behaves like a singular full nominal.

Faatu dajeele-na fécckati ak (a-b) woykat.

Faatu gather-NA.3SG dancer with (INDEF-CM.SG) singer

'Faatu gathered a dancer with a singer.'

A second argument is provided by discourse anaphora. Expectedly, a pronoun must match number of a full nominal antecedent.
a. Gis-na-a a-b jangalekat. Maymuna bëgg-na ko / see-NA-1 SG INDEF-CM.SG teacher Maymuna like-NA.3SG OBJ.3SG / *leen.
*OBJ.3PL
'I saw a teacher yesterday. Maymuna admires her/*them.'
b. Gis-na-a a-y jangalekat. Maymuna bëgg-na *ko / leen. see-NA-1 SG INDEF-CM.PL teacher Maymuna like-NA.3SG *OBJ.3SG / OBJ.3PL 'I saw some teachers yesterday. Maymuna admires *her/them.'

As we have also already seen, under the same circumstances, a BN behaves like the singular full nominal (cf. Mandarin (6a)). ${ }^{2}$
Gis-na-a jangalekat. Maymuna bëgg-na ko / *leen.
see-NA-1SG teacher Maymuna like-NA.3SG OBJ.3SG / *OBJ.3PL
'I saw a teacher yesterday. Maymuna admires her/*them.'

Third, a BN cannot be the antecedent of a reciprocal or of a plural reflexive. A full plural nominal, as expected, can.
a. Jangalekat $b-i$
wanale-na
a-y
nonggo darra ñu
teacher
CM.SG-DEF introduce-NA.3SG CM.PL-INDEF student 3PL
xam-ante.
know-RECIP
'The teacher introduced some students to each other.'
b. *Jangalekat b-i wanale-na nonggo darra ñu xam-ante. teacher CM.SG-DEF introduce-NA.3SG student 3PL know-RECIP Lit.: 'The teacher introduced student to each other.'
a. Kadeer sang-oloo-na xale $y-i \quad$ seen bopp.
Kadeer wash-CAUS-NA.3SG child CM.PL-DEF POSS.3PL head
'Kadeer made the children wash themselves.' teacher CM.SG-DEF wash-CAUS-NA.3SG student POSS.3PL head Lit.: 'The teacher made student wash themselves.'
b. Jangalekat $b-i \quad$ sang-oloo-na nonggo darra seen bopp.

In sum, the data investigated above suggest that BNs in Wolof are singular, and not number neutral, even though this is claimed to a cross-linguistically stable property of BNs. We may then ask the following question: how can we account for the exclusively singular interpretation (and

\footnotetext{
${ }^{2}$ Similar data can be reproduced with interrogative pronouns in sluicing contexts.
} 
not number neutral) interpretation of BNs in Wolof?

However, the generalization that BNs in Wolof are singular only holds if they are unmodified. If there is plural morphology in the nominal, either in the form of complementizer agreement or possessum agreement, the $\mathrm{BN}$ has a plural interpretation. In the next section, we will see that the addition of modifiers may have a pluralizing effect in the BN. If the modifier does not expone a plural feature, the BN thus modified remains exclusively singular. In $\S 4$, we will see a similar contrast in the behavior of two possessive nominals. If the possessive construction contains plural morphology, a $\mathrm{BN}$ is interpreted in the plural. If the possessive nominal does contain any number morphology, no pluralizing effect is witnessed.

3. Adding a modifier: relative clauses vs. plain modifiers. Nominal modifiers in Wolof predominantly have the syntax of a relative clause. The exception are expressions for nationalities. Either one of these modifiers can combine with BNs, but each option has consequences for the number interpretation of the BN. This contrast will serve as the basis for the proposal to be put forth in this paper, where the source of number interpretation in Wolof BNs is nominal-internal. We discuss each modifier in turn.

In Wolof, a relative clause contains a class marker attached to the relative complementizer $u$ (Torrence, 2013). As mentioned above, the same morpheme is found attached to determiners. The class marker of the relative clause and that of the head of the relative clause must match.
a. Samba tej-na
palanteer [ b-u
tilim ] b-i.
/*y-i
Samba close-NA.3SG window [ CM.SG-COMP dirty ] CM.SG-DEF / *CM.PL-DEF
'Samba closed the window that is dirty.'
b. Samba tej-na palanteer $[y-u \quad$ tilim $]$ y-i $\quad$ / b b-i.
Samba close-NA.3SG window [ CM.PL-COMP dirty ] CM.PL-DEF / *CM.SG-DEF
'Samba closed the windows that are dirty.'

BNs can be modified by a relative clause with either a singular or a plural class marker.

$$
\text { Samba tej-na palanteer }[\mathrm{b}-\mathrm{u} \quad \text { tilim }] /[\mathrm{y}-\mathrm{u} \quad \text { tilim }] \text {. }
$$

Samba close-NA.3SG window [ CM.SG-COMP dirty ] / [ CM.PL-COMP dirty ]

'Samba closed some window that is dirty/some windows that are dirty.'

We saw in $\$ 2$ that BNs in Wolof are singular and that they behave like a singular full DP. We may ask then how they can be able to be modified by a relative clause with a plural class marker $(y)$, while their singular full DP counterpart cannot (19b). In fact, the behavior of BNs now resembles that of plural DPs (19b). We may further ask if BNs modified by a plural relative clause may behave like full plural DPs in other aspects as well. In this section, we will go back to the properties investigated above and see that the answer to this question is positive.

A BN modified by a plural RC can be the object of the collective predicate dajeele 'gather' (21). It can, in fact, must, be referred back to with a plural pronoun (22). It can also be the antecedent of a reciprocal (23) and of a plural reflexive (24). ${ }^{3}$

\footnotetext{
${ }^{3}$ A singular relative clause, with the singular class marker $b$ can also be used to modify a BN, but I omit the data for space limitation reasons (see Fong 2019). It behaves like a singular full nominal, just like the unmodified BN data in $\S 2$.
} 
Jangalekat b-i dajeele-na xale [y-u Samba xam ] ci bayaal teacher CM.SG-DEF gather-NA.3SG child [ CM.PL-COMP Samba know ] PREP park b-i.

CM.SG-DEF

'The teacher gathered some students who Samba knows in the park.'

Gis-na-a jangalekat [ $y-u \quad$ Roxaya xam ]. Maymuna bëgg-na

see-NA-1SG teacher [ CM.PL-COMP Roxaya know ] Maymuna like-NA.3SG

*ko / leen.

* OBJ.3SG / OBJ.3PL

'I saw some teachers who Roxaya knows. Maymuna admires them.'
Jangalekat b-i
wanale-na
nonggo darra $[\mathrm{y}-\mathrm{u}$
Mareem xam
teacher CM.SG-DEF introduce-NA.3SG student
[ CM.PL-COMP Mareem know
] ñu xam-ante.
] 3PL know-RECIP
'The teacher introduced student that Mareem knows to each other.'

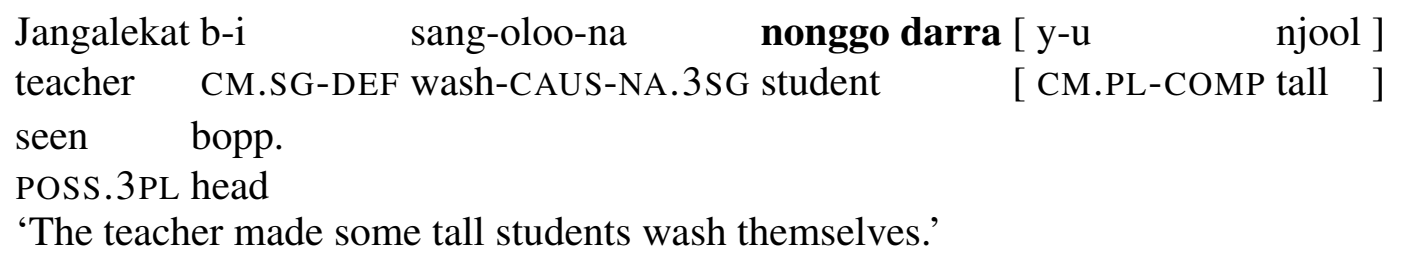

From these data, one may conclude that BNs in Wolof can also have the behavior of a plural nominal, as long as they merge with a modifier with plural morphology.

Nevertheless, there are modifiers that do not contain any number morphology. A case in point are expressions that indicate nationality, which do not have the syntax of relative clauses.

$$
\begin{aligned}
& \text { Mareem dajeele-na a-y woykat brezilien. } \\
& \text { Mareem gather-NA.3SG INDEF-CM.PL singer } \\
& \text { 'Marazilian } \\
& \text { Mareem gathered some Brazilian singers.' }
\end{aligned}
$$

The "pluralizing" effect on BNs brought about by the plural relative clause can be compared with the absence of this effect when a BN is merged with a plain modifier: in that case, a BN retains its exclusively singular interpretation. ${ }^{4}$

(26) Roxaya dajeele-na fécckat brezilien.

Roxaya gather-NA.3SG dancer Brazilian

Lit.: 'Roxaya gathered Brazilian student.'

(27) Gis na-a woykat brezilien. Maymuna bëgg na ko /*leen. see NA-1SG dancer Brazilian Maymuna like NA.3SG OBJ.3SG / *OBJ.3PL 'I saw a Brazilian dancer. Maymuna admires her/*them.
Jangalekat b-i
desin-ante-loo-na
nonggo darra brezilien.
teacher CM.SG-DEF draw-RECIP-CAUS-NA.3SG student
Brazilian
Lit.: 'The teacher made student draw each other.'

\footnotetext{
${ }^{4}$ Regrettably, I do not have plural reflexive data for BNs modified by brezilien.
} 
Plain modifiers like those that express nationalities do not have a pluralizing effect, like relative clauses do. Why does an unmodified $\mathrm{BN}$ behave as if it were singular, while a BN modified by a plural relative clause behaves as if it were plural? Why does adding a plain (i.e. numberless) nominal modifier not have the same effect? Before we move on to an analysis, we will examine two possessive constructions from which we can draw the same questions.

4. Two types of possessive nominals. In Wolof, there are at least two types of possessive nominals. In (29), the possessive determiner sama 'my' is used. It precedes the possessum $x a j$ 'dog'. A definite determiner $b i$ 'the' can be part of the same nominal. In (30), the genitive suffix $u$ is used. It is affixed to the possessum muus 'cat', which precedes the possesor Mareem.

Gis-na-a sama xaj b-i ci baayal b-i.

see-NA-1SG POSS.1SG dog CM.SG-DEF PREP park CM.SG-DEF 'I saw my dog in the garden.'
Toogakat b-i
gis-na a-y
muus-u Mareem (...).
cook CM.SG-DEF see-NA.3SG INDEF.CM.PL cat-GEN Mareem
'The cook saw some cats of Mareem's.'

These constructions differ in whether or not they contain some number morphology. When a BN is used in these possessive constructions, their behavior resemble that of plural relative clauses and plain modifiers. We discuss each possessive construction in turn.

Starting with (29), the possessive determiner may be suffixed with a morpheme that is sensitive to the number of the possessum. If the possessum is singular, $-y$ may not occur (31a); the opposite holds when the possessum is plural (31b). ${ }^{5}$
a. Gis-na-a sama(*-y) xaj b-i ci baayal b-i. see-NA-1SG POSS.1SG(*-PL) dog CM.SG-DEF PREP park CM.SG-DEF 'I saw my dog in the garden.'
b. Gis-na-a sama-y xaj y-i ci baayal b-i. see-NA-1SG POSS.1SG-PL dog CM.PL-DEF PREP park CM.SG-DEF 'I saw my dogs in the garden.'

I assume that this type of possessive nominal has the structure in (32), which represents sama-y xaj $y$ - $i$ 'POSS.1SG-PL dog CM.PL-DEF' (my dogs). In this possessive nominal, the head of Poss $\mathrm{P}$ is proposed to probe for a number feature. This feature is valued by the c-commanded possessum.

\footnotetext{
${ }^{5}$ There should be a version of (31b) where $-y$ is missing and which is presumably ungrammatical. I unfortunately do not have this data.
} 


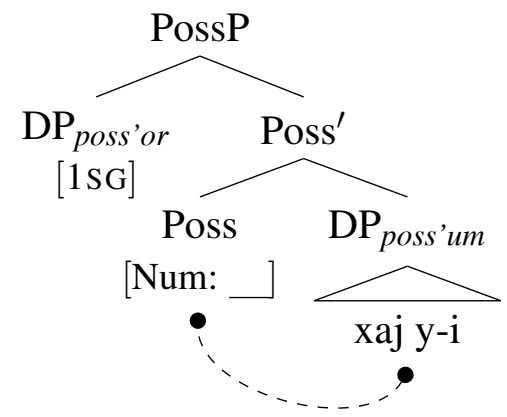

The possessum in this type of possessive construction can be a BN as well. In that case, the possessive determiner may be suffixed with $-y$ or not:
a. sama nit
b. sama-y nit
POSS.1SG person
'my friend'
POSS.1SG-PL person
'my friends'

This range of possibilities mimicks the $b$ - (singular) and $y$ - (plural) relative clauses surveyed above. Only when the plural possessive-sensitive $-y$ is present is a possessum BN interpreted in the plural.

a. Dajeele-na-a sama-y muus ci tool b-i. gather-NA-1SG POSS.1SG-PL cat PREP garden CM.SG-DEF 'I gathered some cats of mine in the garden.'

b. *Dajeele-na-a sama muus ci tool b-i. gather-NA-1SG POSS.1SG cat PREP garden CM.SG-DEF Lit.: 'I gathered a cat of mine in the garden.'

a. Wën-na-a sama-y xaj Mareem. Bëgg-na-a *ko / leen. show-NA-1SG POSS.1SG-PL dog Mareem likeNA-1SG *OBJ.SG / OBJ.PL 'I showed Mareem some dogs of mine. I like *him/them.'

b. Wën-na-a sama xaj Mareem. Bëgg-na-a ko / *leen. show-NA-1SG POSS.1SG dog Mareem likeNA-1SG OBJ.SG / *OBJ.PL 'I showed Mareem a dog of mine. She likes him/*them.'

a. Desin-ante-loo-na-a sama-y doom seen bopp. draw-RECIP-CAUS-NA-1SG POSS.1SG-PL child POSS.3PL head 'I made some children of mine draw each other.'

b. *Desin-ante-loo-na-a sama doom seen bopp. draw-RECIP-CAUS-NA-1SG POSS.1SG child POSS.3PL head Lit.: 'I made child of mine draw each other.'

a. Jangalekat $y-i \quad$ sang-aloo-na-ñu seen- $i \quad$ nonggo darra seen teacher CM.PL-DEF wash-CAUS-NA-3PL POSS.3PL student POSS.3PL bopp. head 'The teachers made some students of theirs wash themselves.' 

b. *Jangalekat y-i sang-aloo-na-ñu seen nonggo darra seen bopp. teacher CM.PL-DEF wash-CAUS-NA-3PL POSS student POSS.3PL head Lit.: 'The teachers student of theirs wash themselves.'

In contrast, the genitive $-u$ is not sensitive to the number of the possessum and only a singular interpretation arises (38). ${ }^{6}$

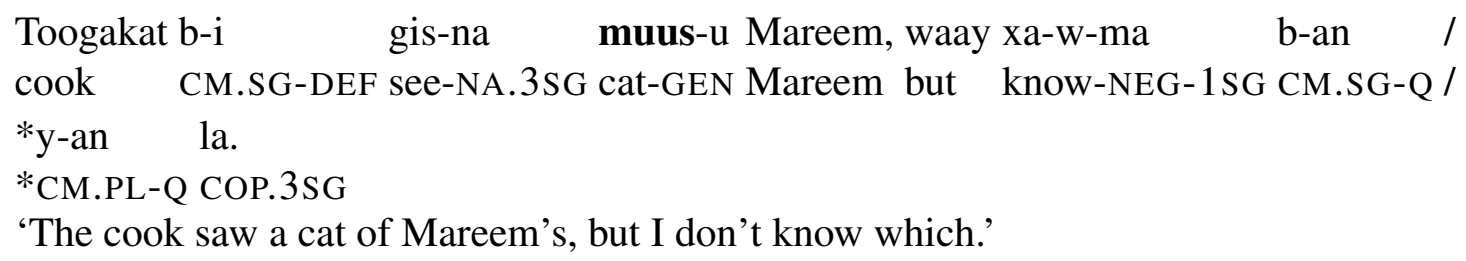

I assume the structure in (39) for genitive possessives, illustrated with $a-b$ muus- $u$ Samba 'INDEFCM.SG cat-GEN Samba' (a cat of Samba's). For concreteness, I assume Den Dikken's (2006) Relator Phrase, whose head is realized by the genitive morpheme $-u$. Contrary to the possessive in (32) examined above, in the genitive (39), there is no probe for number.

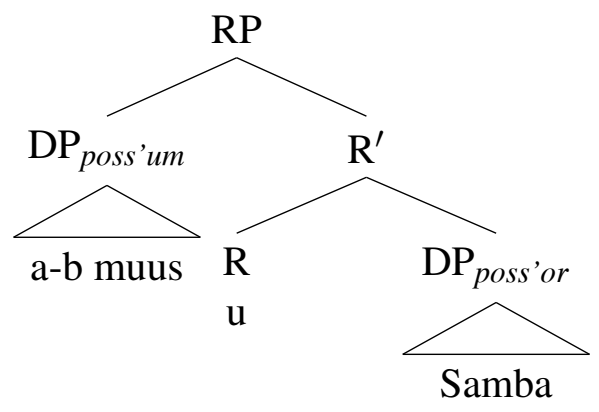

The absence of number morphology in this type of possessive construction is correlated with the unavailability of a plural reading for the $\mathrm{BN}:{ }^{7}$
Roxaya boole-na хај-
Kadeer *( ak xaj-u Kumba ). Roxaya put.together-NA.3SG dog-GEN Kadeer *( CONJ dog-GEN Kumba ) 'Roxaya put together Kadeer's dog *(with Kumba's dog).'
Gis-na-a muus-u Kadeer ci tool b-i.
Bëgg-na-a ko / see-NA-1 SG cat-GEN Kadeer PREP garden CM.SG-DEF like-NA-1SG OBJ.3SG /
*leen.
*OBJ.3PL
'I saw a cat of Kadeer's in the garden. I like him;her/*them.'
*Roxaya wanale-na
jangalekat-u Mareem ñu xam-ante.
Roxaya introduce-NA.3SG teacher-GEN Mareem 3PL know-RECIP
Lit.: 'Roxaya introduced a teacher of Mareem's to each other.'

\footnotetext{
${ }^{6}$ In (38), the number of the possessum is revealed by an obligatorily singular interrogative pronoun (ban). Muus is a BN because this construction can have a determiner: $a-y$ muus- $u$ Mareem 'some cats of Mareem's'.

${ }^{7}$ Regrettably, I do not have plural reflexive data to illustrate genitive possessives.
} 
Isaa sang-oloo-na $\quad$ xaj-u Kadeer bopp=am /*seen bopp.

Isaa wash-CAUS-NA.3SG dog-GEN Kadeer head=POSS.3SG / *POSS.3PL head

'Isaa made a dog of Kadeer's wash himself/themselves.'

The emergent generalization is that BNs in Wolof are singular, unless there is nominalinternal morphology that expones a plural feature. The latter can be realized as relative complementizer agreement or possessum agreement. In the absence of such an exponent, which happens when the $\mathrm{BN}$ is unmodified or when the modifier is itself number-less, the $\mathrm{BN}$ is construed in the singular, exclusively. In the next section, I propose an analysis that is based on the extension of an independent analysis of Person Case Constraint phenomena.

5. Analysis. In order to account for the PCC (Person Case Constraint), Béjar \& Rezac (2009) propose the following condition:

(44) Person-Licensing Condition (Béjar \& Rezac, 2009, (13))

A $\pi$-feature $[\mathrm{F}]$ must be licensed by Agree of some segment in a feature structure of which $[\mathrm{F}]$ is a subset.

Kalin $(2017,2019)$ argues for a generalized version of (44) where interpretable, valued features are responsible for nominal licensing. The empirical support that Kalin furnishes is a series of similarities between the PCC and DOM (Differential Object Marking). The author contends that a unified analysis can be provided that is based on the need of certain interpretable nominal features to be licensed via Agree.

In a similar vein, a I propose a further extension of the PLC (44) to the marked number feature, i.e. plural: ${ }^{8}$

\section{Number-Licensing Condition}

A marked number feature (i.e. plural) must be licensed by Agree.

I will argue that (45) can account for the number interpretation restrictions observed in the distribution of BNs in Wolof.

The first step in the analysis is to provide a structure for full nominals, as this will allow us to better grasp the missing elements in a BN. To recall, BNs in Wolof lack both a(n overt) determiner and the class marker affixed to it. I hypothesize that a $\mathrm{BN}$ has a truncated structure. Under this view, we must then ask which nominal layers are missing in a $\mathrm{BN}$.

Torrence (2013) analyzes the class marker that is prefixed to the relative complementizer $u$ as an instance of complementizer agreement. I extend this analysis and propose that the class marker that appears affixed to determiners is also the result of Agree. A suggestion that this proposal is on the right track is supplied by the fact that a class marker can appear more than once in the same nominal (46a). In this case, the class markers must match (46b).

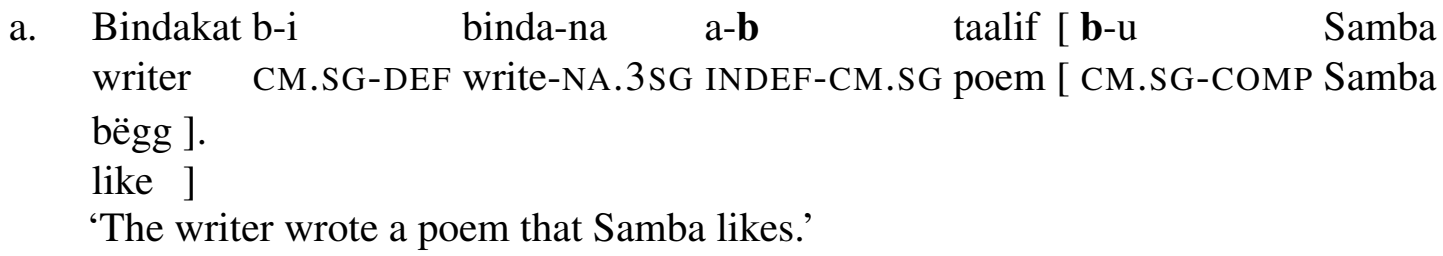

${ }^{8}$ Due to space limitations, I do not discuss here alternative analyses; see Fong (2019). 

b. Samba tej-na
palanteer [ b-u
tilim ] b-i.
$/ * \mathbf{y}-\mathrm{i}$
Samba close-NA.3SG window [ CM.SG-COMP dirty ] CM.SG-DEF / *CM.PL-DEF
'Samba closed the window that is dirty.'

The Wolof class markers can be found in (47).

\begin{tabular}{|c|c|c|c|c|}
\hline & Number & Noun & CM-DEF & Gloss \\
\hline a. & \multirow[t]{9}{*}{ Singular } & yàmbaa & $\mathrm{j}-\mathrm{i}$ & 'marijuana CM.SG-DEF' \\
\hline b. & & nit & $\mathrm{k}-\mathrm{i}$ & 'person CM.SG-DEF' \\
\hline c. & & xaj & $b-i$ & 'dog CM.SG-DEF' \\
\hline d. & & nit & $\mathrm{k}-\mathrm{i}$ & 'person CM.SG-DEF' \\
\hline e. & & mbagg & $\mathrm{m}-\mathrm{i}$ & 'shoulder CM.SG-DEF' \\
\hline f. & & weñ & $w-i$ & 'metal CM.SG-DEF' \\
\hline $\mathrm{g}$ & & suuf & $s-i$ & 'ground CM.SG-DEF' \\
\hline h. & & ndap & $1-i$ & 'pot CM.SG-DEF' \\
\hline i. & & góór & $g-i$ & 'man CM.SG-DEF' \\
\hline $\mathrm{j}$. & \multirow[t]{2}{*}{ Plural } & xaj & $y-i$ & 'dog CM.PL-DEF' \\
\hline $\mathrm{k}$. & & góór & $\tilde{n}-\mathrm{i}$ & 'man CM.PL-DEF' \\
\hline
\end{tabular}

It seems clear from (47) that there are more class markers for singular nouns than for plural ones. We could assume that there are as many vocabulary items as there are class markers. While this potential analysis is consistent with the facts, it misses the asymmetry in the amount of singular and plural class markers. In order to capture these facts, I propose that a class marker is a feature which is a specification of $n$. I follow Acquaviva (2009) in assuming that gender and other rootspecific morphology is encoded in the categorizer that merges with the root. Furthermore, I postulate a single head (AgrP) that probes for a class marker and a number feature. It is this single head (Agr), I contend, that is exponed as the class marker morpheme in (47).

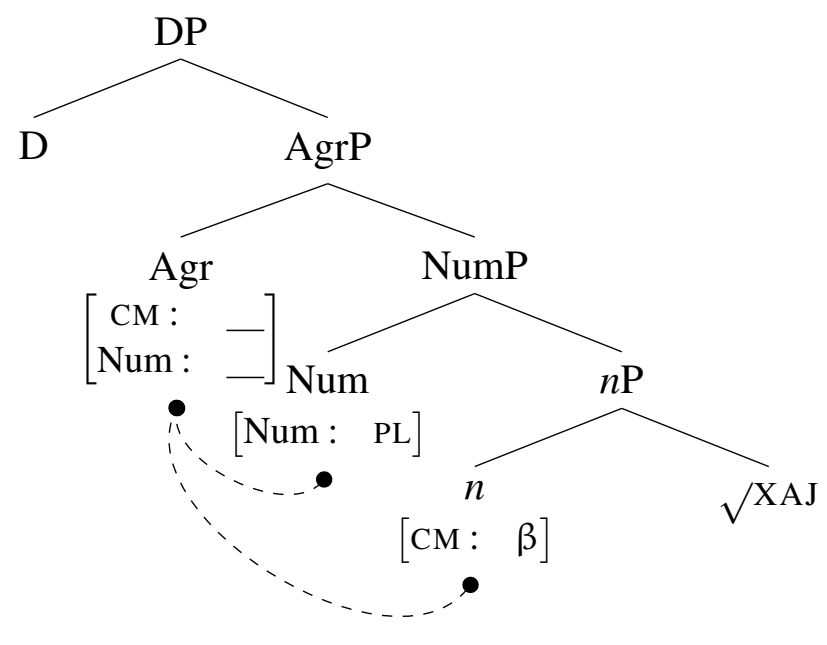

The Vocabulary Items that I assume for class markers are in (49). (For concreteness, I represent 
the class marker feature with a Greek letter that corresponds to the singular class marker.)

$$
\begin{array}{ll}
\text { a. } & {[\mathrm{CM}: \beta] \leftrightarrow / b /} \\
\text { b. } & {[\mathrm{CM}: \kappa] \leftrightarrow / k /} \\
\text { c. } & {[\mathrm{CM}: \mu] \leftrightarrow / m /}
\end{array}
$$

d. $\quad \ldots$

e. $[\mathrm{PLURAL}] \leftrightarrow / y /$

f. $\quad[\mathrm{CM}: \gamma ;$ PLURAL $] \leftrightarrow / \tilde{n} /$

We now have the pieces to derive full nominals like $a$ - $b$ xale 'a child' (INDEF-CM.SG child) and $a-y$ xale 'some children' (INDEF-CM.SG child). In both (50a) and (50b) the root and hence the class marker in $n$ are the same. What differs is the number: singular in (50a) and plural in (50b). The exponent of Agr in (50a) is thus $b$ (49a) and in (50a), $y(49 \mathrm{e})$.

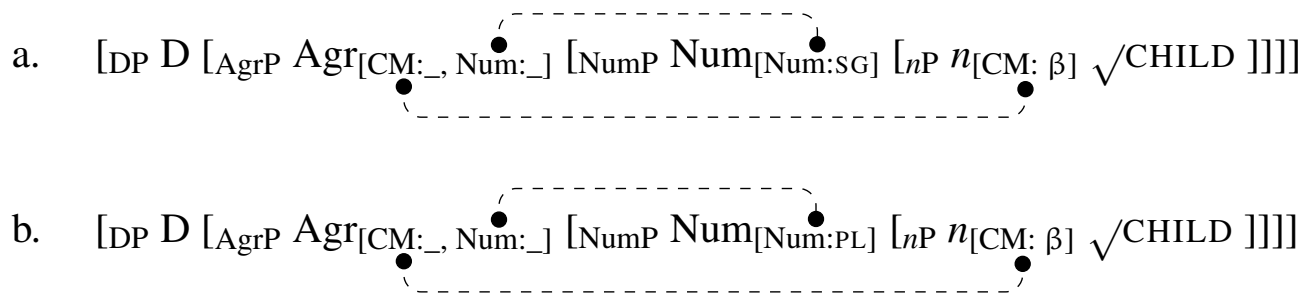

In the plural nominal (50b), the stipulated NLC (45) can be satisfied because Agr has a Number feature to be valued, thereby licensing the marked plural feature via Agree. (50a) satisfies the NLC vacuously due to the absence of a plural feature.

As mentioned, I assume that BNs have a truncated structure; this has already been proposed for BNs in other languages (cf. Massam 2001, a.o.) Specifically, I propose that BNs in Wolof lack an AgrP layer, since they lack a class marker, here, to reiterate, analyzed as the exponent of Agree. Conversely, NumP is retained under the assumption that this is the only locus of number interpretation (Ritter, 1991, 1992; Harbour, 2011). Hence, the BN structure is as in (52) below. (I am so far agnostic regarding the projection of a silent DP layer.)

All things equal, since Wolof has both singular and plural full nominals, I hypothesize that the same range of possibilities should be available to BNs as well. A potential suggestion that BNs can indeed have a number feature is provided by the fact that they can (in fact, must) be cross-referenced by plural morphology when conjoined in the subject position.

$$
\begin{aligned}
& \text { Xale ak jangalekat *woy-na / woy-na-ñu ci daara j-i. } \\
& \text { child with teacher *sing-NA.3SG / sing-NA-3PL PREP school CM.SG-DEF } \\
& \text { 'A child and a teacher sang in the school.' }
\end{aligned}
$$

A question that arises at this juncture is how we could exclude a plural interpretation, which BNs cannot display when unmodified.

$$
\text { a. [NumP Num }\left[\text { Num:SG] }[n P \text { } n \sqrt{ }]_{B N}\right.
$$

b. $*_{[\text {NumP }}$ Num $_{[\text {Num:PL }]}[n P$ $\left.n \sqrt{ }]\right]_{B N}$

I proposed that BNs lack an Agr projection. Consequently, unlike what happens in the full nominal, there is no source of licensing for an interpretable plural feature if a BN is thus specified (52b). Only a BN with a [SINGULAR] Num could converge (52a). This would be why, according to this analysis, BNs in Wolof are exclusively singular: there are in principle two possible 
derivations, depending on whether the $\mathrm{BN}$ is singular or plural, however, only one of them yields a representation that complies with (45).

With these tools in hand, we can move on to the derivation of relative clauses that modify BNs. Following Torrence (2013), assume a raising analysis for relative clauses in Wolof. Also following this author, I assume that the class marker that appears affixed to the relative complementizer is the result of complementizer agreement. For uniformity, I assume that this class marker is also the exponent of an Agr projection now at the relative CP level and which is probing for both a number and a class marker feature. (53) is a partial derivation where the BN is still inside the CP. The Agr below CP probes down to value its [NUMBER] and [CM] features. It encounters the matching features in the BN (in boldface).

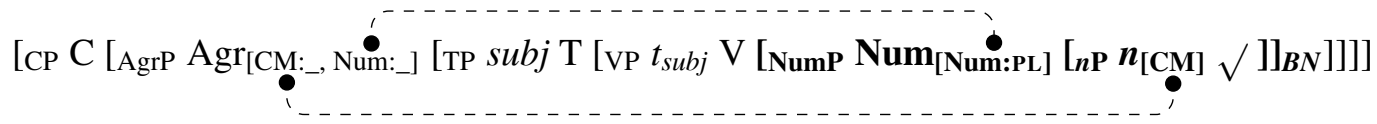

In this structure, even though the BN itself does not have a [NUMBER] licenser (i.e. a matching probe that Agrees with it), the Agr at the CP level. The NLC (45) in this case can be complied with, hence why a BN can have a plural interpretation in this case. ${ }^{9}$

Licensing of [NUMBER] by Agree is also possible in the possessive construction, if the possessum-sensitive $y$ is the exponent of Agree. The derivation of (33b) would be as in (54), where the possessive determiner is the head of a PossP and in which it bears an unvalued [NUMBER] feature that can be valued by the matching feature in the BN.

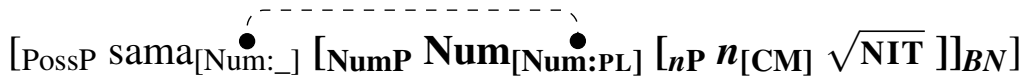

Finally, in the number-less possessive construction (55), there is no probe to Agree with the [PLURAL] number of the BN, so, again, only a [SINGULAR] derivation converges.

$$
{ }^{*}\left[\mathrm{RP}\left[\mathrm{NumP} \operatorname{Num}_{[\mathrm{Num}: \mathbf{P L}]}\left[n \mathbf{P} \boldsymbol{n}_{[\mathrm{CM}]} \sqrt{\mathrm{MUUS}}\right]\right]_{\boldsymbol{B N}}\left[\mathrm{R}^{\prime} \mathrm{R}_{-u}[\mathrm{Mareem}]\right]\right]
$$

In brief, the analysis proposed to account for the exclusively singular (as opposed to the more commonly attested number neutrality) interpretation of BNs in Wolof by proposing that it obeys the NLC (45). This is a condition that imposes that [PLURAL] be licensed via Agree, an extension of Béjar \& Rezac's condition on [PARTICIPANT] features and, more generally, of Kalin's (2017; 2019) nominal licensing system.

6. Concluding remarks. In this paper, we investigated BNs in Wolof. Specifically, the goal was to provide answers to the questions in (10). Unlike what happens in other languages, BNs in this language are not number neutral, but rather exclusively singular. However, this generalization only holds if the $\mathrm{BN}$ is unmodified and there is no morphology exponing a plural feature. This is the case of relative clauses, where there is complementizer agreement and possessive nominals where there is agreement with the possessum. In order to account for this generalization, I proposed an extension to Béjar \& Rezac's (2009) PLC to number (the NLC in (45)). If correct, this

\footnotetext{
${ }^{9}$ (52) is a simplified diagram, where $v \mathrm{P}$ and $\overline{\mathrm{A}}$-movement of the $\mathrm{BN}$ object to the phase edge are omitted for vis-
} ual simplicity. 
analysis accounts for the typologically unusual behavior of BNs in Wolof and provides support for the view that valued features may be responsible for nominal licensing (Kalin, 2017, 2019).

\section{References}

Acquaviva, Paolo. 2009. Roots and lexicality in Distributed Morphology. York Papers in Linguistics 2(10). 1-21. https://www.york.ac.uk/language/ypl/ypl2/10/YPL2-10-01Acquaviva.pdf.

Babou, Cheikh Anta \& Michele Loporcaro. 2016. Noun classes and grammatical gender in Wolof. Journal of African Languages and Linguistics 37(1). 1-57. https://doi.org/10.1515/jall-2016-0001.

Béjar, Susana \& Milan Rezac. 2009. Cyclic agree. Linguistic Inquiry 40(1). 35-73. https://doi.org/10.1162/ling.2009.40.1.35.

Corbett, Greville. 2000. Number. Cambridge: Cambridge University Press.

Den Dikken, Marcel. 2006. Relators and linkers: The syntax of predication, predicate inversion, and copulas. Cambridge, MA: MIT Press.

Fong, Suzana. 2019. Feature licensing and the interpretation of bare nominals in Wolof. Ms. Massachusetts Institute of Technology.

Harbour, Daniel. 2011. Valence and atomic number. Linguistic Inquiry 42(4). 561-594. https://doi.org/10.1162/LING a 00061.

Jenks, Peter. 2018. Articulated definiteness without articles. Linguistic Inquiry 49(3). 501-536. https://doi.org/10.1162/ling_a_00280.

Kalin, Laura. 2017. Dropping the F-bomb: An argument for valued features as derivational timebombs. In Andrew Lamont \& Katerina Tetzloff (eds.), Proceedings of the forty-seventh Annual Meeting of the North East Linguistic Society. 119-132. University of Massachussets: GLSA.

Kalin, Laura. 2019. Nominal licensing is driven by valued (phi-) features. Nordlyd 43(1). 15-29. https://doi.org/10.7557/12.4186.

Massam, Diane. 2001. Pseudo noun incorporation in Niuean. Natural Language \& Linguistic Theory 19(1). 153-197. https://doi.org/10.1023/A:1006465130442.

Ritter, Elizabeth. 1991. Two functional categories in Modern Hebrew noun phrases. In Susan Rothstein (ed.), Syntax and semantics: Perspectives on phrase structure: Heads and Licensing. 37-60. New York: Academic Press.

Ritter, Elizabeth. 1992. Cross-linguistic evidence for number phrase. Canadian Journal of Linguistics/Revue canadienne de linguistique 37(2). 197-218. https://doi.org/10.1017/S0008413100021952.

Rullmann, Hotze \& Aili You. 2006. General number and the semantics and pragmatics of indefinite bare nouns in Mandarin Chinese. In Klaus von Heusinger \& Ken Turner (eds.), Where semantics meets pragmatics. 175-196. Amsterdam: Elsevier.

Tamba, Khady, Torrence, Harold, \& Zimmermann, Malte. 2012. Wolof quantifiers. In Edward L. Keenan \& Denis Paperno (eds.), Handbook of quantifiers in natural language. 891-939. Dordrecht: Springer.

Torrence, Harold. 2013. The clause structure of Wolof: Insights into the left periphery. Amsterdam: John Benjamins. https://doi.org/10.1075/la.198. 